05

\title{
Волна фазового превращения \\ в деформируемых аустенитных сталях, облученных в реакторе БН-350, и условия ее реализации
}

\section{(C) О.П. Максимкин}

Институт ядерной физики Министерства энергетики

Республики Казахстан, Алматы, Казахстан

Национальный исследовательский ядерный университет „МИФИ“,

Москва, Россия

E-mail: maksimkin@inp.kz

Поступило в Редакцию 22 января 2018 г.

Анализируются экспериментальные данные по влиянию нейтронного облучения на пластические свойства аустенитных хромоникелевых сталей. Особое внимание обращено на регистрацию аномально высоких значений пластичности, достигаемых при некоторых параметрах облучения и деформации, что объясняется образованием и перемещением в метастабильной стали „волны фазового перехода“. Сформулированы необходимые и достаточные условия наличия „волны“.

DOI: $10.21883 /$ PJTF.2018.14.46339.17221

Общеизвестно и общепризнано, что в результате высокодозного нейтронного облучения пластичность реакторных аустенитных сталей катастрофически уменьшается с ростом потока бомбардирующих ядерных частиц $[1,2]$. В то же время в ходе исследований изменений структуры и свойств материалов чехлов отработавших тепловыделяющих сборок ядерного реактора БН-350 мы неоднократно наблюдали аномально высокие $(\sim 35 \%)$ значения пластичности коррозионностойкой хромоникелевой стали $12 \mathrm{Cr} 18 \mathrm{Ni10Ti}$, облученной вплоть до повреждающей дозы 56 смещений на атом (dpa) [3,4]. Этот эффект был связан с регистрацией на диаграмме напряжение $(\sigma)$-деформация $(\varepsilon)$ площадки текучести, обусловленной распространением макрополос типа Чернова-Людерса вдоль образца. При этом деформация развивалась путем зарождения и перемещения волны пластической деформации, во 

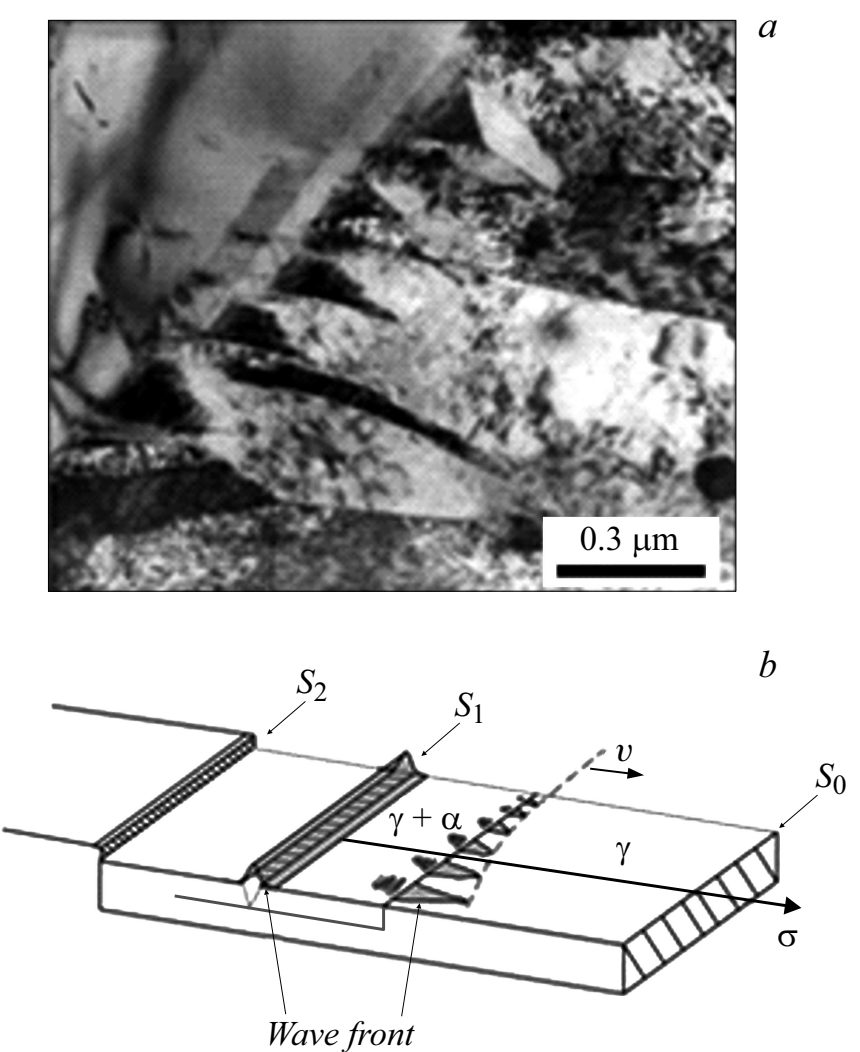

Рис. 1. Полученный методом просвечивающей электронной микроскопии снимок $\alpha^{\prime}$-мартенситных образований $(a)$ и образец стали $12 \mathrm{Cr} 18 \mathrm{Ni10 \textrm {Ti }}$, деформированный со скоростью $v$ под действием растягивающего напряжения $\sigma(b)$. Перед фронтом первой волны структура стали $-\gamma$-решетка, за фронтами волн $\left(S_{1}, S_{2}\right)$ - структура $\gamma+\alpha$.

фронте которой протекало фазовое мартенситное $\gamma \rightarrow \alpha^{\prime}$-превращение, сопровождающееся образованием в парамагнитной $\gamma$-матрице (ГЦКрешетка) более прочной ферромагнитной $\alpha$-фазы (ОЦК-решетка) [5] (рис. 1). Аналогичный эффект был обнаружен [6] при низкотемпературной $\left(-100^{\circ} \mathrm{C}\right)$ деформации высокооблученной нейтронами аустенитной

Письма в ЖТФ, 2018, том 44, вып. 14 
стали 08Cr16Ni11Mo3, характеризующейся более высокой энергией дефекта упаковки [7]. Следует отметить, что при скорости деформирования $8 \cdot 10^{-3} \mathrm{~mm} / \mathrm{s}$ скорость перемещения волны в образце оказалась значительно выше и составила $3 \cdot 10^{-2} \mathrm{~mm} / \mathrm{s}$.

Задача настоящей работы - обобщить полученные результаты и сформулировать условия зарождения и перемещения „волны фазового перехода“ в высокооблученных аустенитных сталях.

Электронно-микроскопические и металлографические исследования показали, что механизмы деформации необлученных и высокооблученных коррозионно-стойких сталей существенно различаются. Так, в образцах, при растяжении которых зафиксирована площадка текучести, практически не выявляются линии скольжения, но при этом явно выражены следы макродеформации, обусловленные образованием и перемещением деформационных полос, а также наблюдается вытянутость зерен вдоль оси растяжения облученного образца.

Было высказано предположение, что последовательно проводимые в этих экспериментах термическое, радиационное и механическое воздействия на реакторные материалы (аустенизация, нейтронное облучение, давление теплоносителя, охлаждение до отрицательных температур, растяжение) формируют в кристаллической решетке сложнонапряженное состояние, которое приводит к достижению в некоторых участках деформируемого образца напряжений, соответствующих критическим, необходимым для зарождения мартенситной $\alpha$-фазы и/или локализации деформации.

Приведенные в последнее время в научной литературе экспериментальные результаты свидетельствуют о том, что реакторные аустенитные стали после высоких доз облучения (до $150 \mathrm{dpa),} \mathrm{некоторых} \mathrm{видов}$ термообработки и при определенных параметрах испытаний действительно способны проявлять высокую пластичность $[8,9]$. Эти данные значительно выделяются на фоне широко распространенных результатов, свидетельствующих о резком снижении пластичности (до $2-12 \%$ ) с повышением дозы облучения и обнаружении так называемого явления низкотемпературного $\left(20-300^{\circ} \mathrm{C}\right)$ охрупчивания реакторных сталей. На рис. 2 суммированы литературные сведения и данные автора по влиянию нейтронного облучения на пластичность стали $12 \mathrm{Cr} 18 \mathrm{Ni10 \textrm {Ti }}$. Пунктиром показана кривая зависимости общей деформации $\varepsilon$ от повреждающей дозы; значения $\varepsilon$, не вписывающиеся в привычные общепринятые представления, соответствуют центрам кружков, внутри

Письма в ЖТФ, 2018, том 44, вып. 14 


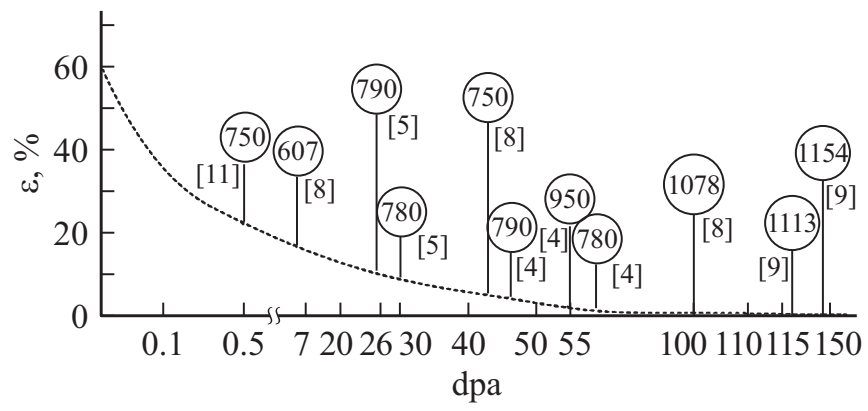

Рис. 2. Влияние повреждающей дозы нейтронного облучения на пластичность стали $12 \mathrm{Cr} 18 \mathrm{Ni10Ti}$ в процессе статического растяжения при $T=20^{\circ} \mathrm{C}$. Пояснения приведены в тексте.

которых приведены величины пределов текучести (в МРа). В скобках указаны литературные ссылки.

Из рис. 2 видно, что даже при воздействии на реакторную сталь больших потоков нейтронов, приводящих к существенной повреждаемости (23-150 dpa) материала, значения пластичности остаются сравнительно высокими.

Результаты механических испытаний „на одноосное растяжение“, демонстрирующие высокие значения $\varepsilon$, свидетельствуют как минимум о двух различных состояниях деформируемой стали, характеризующихся сравнительно низкими или, напротив, высокими значениями предела текучести. Установлено, что этим двум состояниям соответствуют два различных вида диаграмм напряжение-деформация, регистрируемых в экспериментах на растяжение облученных метастабильных сталей при комнатной температуре. В том случае, когда внутренние напряжения в облученной стали $12 \mathrm{Cr} 18 \mathrm{Ni10 \textrm {Ti }}$ (определяемые значением предела текучести) достигают или превосходят величину критического напряжения, соответствующего началу индуцированного деформацией мартенситного $\gamma \rightarrow \alpha$-превращения $\left(\sigma_{c r}=670-750 \mathrm{MPa}\right)$, диаграмма растяжения имеет вид, сочетающий площадку текучести и область параболического деформационного упрочнения, похожую на диаграмму растяжения необлученного материала. Вероятнее всего, что такая диаграмма получается в результате действия в основном двух механизмов пластической деформации: перемещения волны фазового

Письма в ЖТФ, 2018, том 44, вып. 14 
перехода (вследствие реализации $\gamma \rightarrow \alpha$-превращения с оптимальной интенсивностью) и скольжения дислокаций.

Если же предел текучести термообработанной стали после облучения, а затем деформирования при некоторых параметрах растяжения $\left(T_{\text {test }}\right.$ и $\left.V_{\text {test }}\right)$ достигает величины, соответствующей началу образования локализованной деформации (шейки) при $\sigma_{c r} \sim 1000 \mathrm{MPa}[10]$, диаграмма растяжения имеет ярко выраженную площадку текучести, что, вероятно, свидетельствует об образовании и перемещении волны фазового превращения.

Установлено, что увеличение пластичности высокооблученных реакторных сталей обусловлено определенным сочетанием воздействия термической обработки, дозы нейтронного облучения и параметров деформации, которое приводит к возникновению в материале высоких внутренних напряжений, необходимых не только для реализации $\gamma \rightarrow \alpha$-перехода, но и для достижения некоторой оптимальной интенсивности фазового превращения во фронте волны, что обеспечивает так называемый „трип-эффект“ $[11]$.

Таким образом, для приобретения облученной аустенитной сталью высокой пластичности нужно реализовать необходимое и достаточное условие зарождения и непрерывного перемещения волны фазового $\gamma \rightarrow \alpha$-превращения. Необходимым условием зарождения волны является создание (облучением, температурой испытания) в поликристаллическом материале высоких значений внутренних напряжений, равных или бо́льших, чем критическое напряжение зарождения $\alpha$-фазы. Достаточным условием для перемещения волны в деформируемом образце стали является обеспечение оптимальной кинетики накопления $\alpha$-фазы, которой можно управлять, изменяя, например, температуру или скорость деформации.

Полученные результаты могут быть полезны при выполнении работ по обеспечению безопасного хранения и обращения с отработавшими тепловыделяющими сборками ядерных реакторов.

\section{Список литературы}

[1] Ибрагимов Ш.Ш., Кирсанов В.В., Пятилетов Ю.С. Радиационные повреждения металлов и сплавов. М.: Энергоатомиздат, 1985. 239 с.

[2] Петкова А.П. // Вопр. атомной науки и техники. Сер.: Физика радиационных повреждений и радиационное материаловедение. 2003. № 3. С. 83-88.

2 Письма в ЖТФ, 2018, том 44, вып. 14 
[3] Максимкин О.П., Тиванова О.В., Сильнягина Н.С. // Сб. докл. 5-й Междунар. конф. „Ядерная и радиационная физика“. Алматы, 2006. Т. 2. C. $408-418$.

[4] Gusev M.N., Maksimkin O.P., Osipov I.S., Garner F.A. // Proc. of the 13th Int. Conf. on fusion reactor materials. Nice, France, 2007. P. 362-368.

[5] Рубан С.В., Максимкин О.П., Гусев М.Н., Рыбин С.В. // Вестн. НЯЦ РК. 2010. B. 2. C. 25-30.

[6] Максимкин О.П., Гусев М.Н. // Физика металлов и металловедение. 2010. T. 110. № 5. C. 524-529.

[7] Максимкин О.П. Дефекты упаковки, их энергия и влияние на свойства облученных металлов и сплавов. Алматы, 2010. 72 с.

[8] Sorokin A.A., Margolin B.Z., Kursevich I.P., Minkin A.J., Neustroev V.S. // J. Nucl. Mater. 2014. V. 444. P. 373-384.

[9] Margolin B., Sorokin A., Shvetsova V., Minkin A., Potapova A., Smirnov V. // J. Nucl. Mater. 2016. V. 480. P. 52-68.

[10] Byun T.S., Farrell K. // Acta Mater. 2004. V. 52. P. 1597-1608.

[11] Tamura I. // Met. Sci. 1982. V. 16. P. 245-253. 